\title{
Educação em tempos de pandemia: (re)vivências na educação infantil durante o distanciamento social
}

\author{
Education in times of pandemic: (re)experiences in early childhood \\ education during social distancing
}

\section{Educación en tiempos de pandemia: (re)vivencias en la educación infantil durante el alejamiento social}

\author{
Aline da Silva Ferreira Aderne' \\ https://orcid.org/0000-000 I-6380-9366 \\ Tays da Silva Ferreira ${ }^{2}$ \\ https://orcid.org/0000-0002-6642-730I
}

\begin{abstract}
Resumo: Diante do distanciamento social, imposto pela Covid-19, para prevenir a contaminação pelo novo coronavírus, repensaram-se práticas considerando-se as necessidades atuais das crianças, sobretudo, o que rege a legislação correlata à educação infantil. Para dar assistência a elas e sua família nesse período, dá-se continuidade ao trabalho desenvolvido no início das atividades letivas de 2020, concretizadas por meio do "Acolhimento e Exploração de Mundo na Infância: vivências no maternal 2 antes e durante o distanciamento social". Pensado para realizar-se no ambiente doméstico, o projeto busca promover práticas que articulem as experiências e os saberes das crianças com os conhecimentos relacionados com o patrimônio cultural, artístico, ambiental, científico e tecnológico. As ações do projeto consideram os eixos estruturantes da educação infantil as brincadeiras, a interação, os direitos de aprendizagem e o desenvolvimento das crianças, que incluem: conviver, brincar, participar, explorar, expressar e conhecer-se.
\end{abstract}

Palavras-chave: Educação infantil. Distanciamento social. Infância.

Abstract: Faced with the social distancing imposed by Covid-19 to prevent contamination by the new coronavirus, practices were rethought considering the current needs of children, especially regarding the legislation related to child education. To assist them and their families during this period, the work developed at the beginning of the teaching activities of 2020 is continued, materialized through the "Welcoming and Exploration of the World in Childhood: experiences in the maternal 2 before and during social distancing". Designed to be carried out in the domestic environment, the project seeks to promote practices that combine children's

\footnotetext{
' Doutora em Educação. Professora do Ensino Básico, Técnico e Tecnológico (EBTT) na Unidade de Educação Infantil Professora Telma Vitória (UEIPTV) da Universidade Federal de Alagoas (UFAL). E-mail: aline.ferreira@progep.ufal.br

${ }^{2}$ Especialista em Análise Ambiental e em Educação Especial e Inclusiva. Professora da Secretaria Municipal de Educação de Maceió (SEMED) na Unidade de Educação Infantil Professora Telma Vitória (UEIPTV) da Universidade Federal de Alagoas (UFAL). E-mail: tayssf@yahoo.com.br
}

Olhar de professor, Ponta Grossa, v. 24, p. I-8, e-16184.055, 2021.

Disponível em <https://revistas2.uepg.br/index.php/olhardeprofessor> 
experiences and knowledge with knowledge related to cultural, artistic, environmental, scientific and technological heritage. The project's actions take into account the structuring axes of children's education, games, interaction, learning rights and development, which include: living together, playing, participating, exploring, expressing and getting to know each other.

Keywords: Early childhood education. Social distance. Childhood.

Resumen: Delante del alejamiento social, impuesto por la Covid-19, para prevenir la contaminación por el nuevo coronavirus, fueron repensadas las prácticas considerándose las necesidades actuales de los niños, sobre todo, en lo que se refiere a la legislación correlacionada a la educación infantil. Para asistir a los niños y sus familias en ese periodo, se da continuidad al trabajo desarrollado en el inicio de las actividades lectivas de 2020, concretizadas por medio del "Acogida y Explotación del Mundo en la Niñez: vivencias en los ciclos iniciales antes y durante el aislamiento social”. Pensado para realizarse en el ambiente del hogar, el proyecto busca promocionar prácticas que articulen las experiencias y los saberes de los niños con los conocimientos relacionados al patrimonio cultural, artístico, ambiental, científico y tecnológico. Las acciones del proyecto consideran los ejes fundamentales de la educación para niños: los juegos, la interacción, los derechos de aprendizaje y el desarrollo de los niños, que incluyen convivir, jugar, participar, explotar, expresarse y conocerse.

Palabras-clave: Educación infantil. Alejamiento social. Niñez.

\section{Tempo de incertezas...}

O ano de 2020 é iniciado na Unidade de Educação Infantil em que atuamos, situada na Universidade Federal de Alagoas - UFAL. A turma pela qual estamos responsáveis é o maternal 2, composto por 15 crianças de 3 a 4 anos, filhas de alunos/alunas e servidores/servidoras da UFAL, bem como residentes nos arredores da Universidade. Cotidianamente, os projetos nascem na unidade conforme os interesses e as demandas apresentadas pelas crianças. Nesse sentido, dois projetos foram pensados e estavam sendo desenvolvidos em paralelo: “Identidade e Autonomia" e "Educação Ambiental". Esses projetos contam com propostas voltadas para o acolhimento das crianças e de sua família, que frequentam a instituição pelo segundo ano, e buscam contribuir no fortalecimento da autonomia das crianças e promover ações para a consciência ambiental.

Seria mais um ano como tantos outros não fosse um acontecimento capaz de abalar o mundo e nos fazer repensar e mudar nossa vida. Chegava ao Brasil o coronavírus - SARSCoV-2 -, que causa a Covid-19. A todo instante, éramos bombardeadas com informações que reforçavam a necessidade de lavar bem as mãos, utilizar álcool em gel e, posteriormente, fazer uso de máscara. $O$ número de pessoas contaminadas e de óbitos só crescia (e continuam crescendo). Por essa razão, estabelecimentos públicos e privados, incluindo escolas, precisaram suspender suas atividades, e somente serviços considerados essenciais continuaram sendo prestados. Profissionais das áreas de Saúde, Segurança, Limpeza e tantos 
outros, que muitas vezes não são reconhecidos, arriscaram, e continuam arriscando, sua vida para atender as demandas provenientes dessa pandemia.

Iniciava-se, assim, o distanciamento social, e com ele, novas sensações. No dia 18 de março, o Ministério da Educação publicou uma portaria (BRASIL, 2020) inicialmente válida por 30 dias, voltada para a substituição das aulas presenciais por aulas em meios digitais. Mas, e a educação infantil, como ficaria? Neste artigo, na condição de professoras da educação infantil, apresentamos nossas vivências e impressões diante dos desafios envolvidos no atual contexto.

\section{Distanciamento social na escola, e agora?}

$\mathrm{Na}$ qualidade de professora, temos consciência de nosso papel social, mas não podemos negar nossas angústias, as dificuldades e o medo. Com o distanciamento social seguido do trabalho remoto, vieram alterações em nosso sono e na rotina. Passamos a "trocar" o dia pela noite e tivemos dificuldade em administrar nossa jornada profissional, acadêmica e doméstica. A sensação inicial era de que estávamos trabalhando muito mais do que costumávamos. Em alguns casos, realmente estávamos! Essa situação gerou medo, ansiedade, dúvidas e incertezas.

Em Alagoas, instituições, especialmente da rede privada, adotaram a prática de atividades on-line em todas as etapas da educação básica, inclusive na educação infantil. Nesses casos, o professorado passou a se comunicar com as crianças por meio de plataformas digitais, mas, na maioria das escolas, aderiu-se à gravação de vídeos que posteriormente foram compartilhados via WhatsApp e Instagram. Essa situação gerou tensão entre as partes envolvidas: crianças, professoras e famílias.

Denunciou-se ao Sindicato dos Professores (Sinpro) de Alagoas e ao Ministério Público do Trabalho (MPT) o trabalho exaustivo a que professores e professoras estavam sendo submetidos, com cobranças demasiadas por parte das instituições. Para que os vídeos fossem aprovados pela gestão e pudessem ser compartilhados, precisavam gravá-los mais de uma vez, o que demandava mais tempo e acabava ultrapassando a carga horária de trabalho. É preciso lembrar, ainda, que a maioria de nós não foi preparada para atuar na educação a distância ao longo de nossa formação. Costumávamos, sim, fazer registros de nossas práticas entre as crianças por meio de fotos e vídeos, mas de forma espontânea, sem que esses materiais fossem 
divulgados amplamente. Dessa forma, o uso de imagem era um fator que gerava preocupação e desconforto.

Além disso, tínhamos clareza de que a legislação não prevê a utilização da educação a distância na educação infantil como complementação da aprendizagem ou em situações emergenciais, como se aplica ao ensino fundamental (BRASIL, 1996). Somadas a esses fatores, consideramos as orientações da Sociedade Brasileira de Pediatria (2019) que chama a atenção para o acesso cada vez mais precoce e indiscriminado dessas tecnologias e recomenda o uso limitado de telas por parte de crianças entre 2 e 5 anos (no máximo I hora por dia), com a supervisão de pais/cuidadores/responsáveis.

Embora concordássemos com a importância de dar assistência às crianças e a sua família, estávamos convictas de que, na maioria dos casos de que tivemos conhecimento, havia muito mais uma tentativa de garantir as mensalidades e o emprego de nossas colegas, no caso a rede privada, que garantir a educação das crianças. No caso da rede pública, as propostas que estavam surgindo mais pareciam uma transposição da educação a distância para a educação infantil ou uma forma de "não ficarmos para trás". A sensação era de que os adultos eram o foco, e não as crianças.

Estávamos preocupadas com nossas crianças e com as famílias, estávamos dispostas a nos adaptar e aprender com a situação, mas não concordávamos em adotar um formato apenas porque outras instituições estavam adotando, sem que houvesse uma reflexão do que estava sendo feito, sem que as necessidades das crianças fossem consideradas. Desse modo, nós professoras dos maternais I e 2, com auxiliares de sala e recreadoras, decidimos articular os projetos que já vinham sendo desenvolvidos em nossas turmas desde o início do ano letivo e, ao mesmo, respeitar a proposta da instituição. Assim, em continuidade às práticas desenvolvidas antes da pandemia, surgiram dois projetos, um desenvolvido pelo maternal I e outro intitulado "Acolhimento e Exploração de Mundo na Infância: vivências no maternal 2 antes e durante o distanciamento social”, executado por nós e explicitado a seguir.

\section{Eis que surgem possibilidades!}

As crianças matriculadas no maternal 2, turma pela qual somos responsáveis, ingressaram em 2019 e frequentam a instituição pelo segundo ano. No início de 2020, para que se sentissem seguras e acolhidas, as professoras que acompanharam a turma no ano 
anterior se disponibilizaram a recebê-las também com a equipe de sala responsável pela turma no ano corrente (professoras, auxiliares de sala e recreadoras). Essa unificação das equipes contribuiu de modo significativo para que as crianças e as famílias ficassem mais tranquilas durante esse retorno.

Em harmonia com essa perspectiva de fortalecimento da relação entre a instituição e a família, o projeto "Acolhimento e Exploração de Mundo na Infância: vivências no maternal 2 antes e durante o distanciamento social" ${ }^{3}$ busca promover práticas que articulem as experiências e os saberes das crianças com os conhecimentos relacionados com o patrimônio cultural, artístico, ambiental, científico e tecnológico. Suas propostas priorizam brincadeiras e interações, em conformidade com as Diretrizes Curriculares Nacionais para a Educação Infantil (BRASIL, 20I0) e consideram os direitos de aprendizagem e desenvolvimento das crianças, que incluem: conviver, brincar, participar, explorar, expressar e conhecer-se em harmonia com a Base Nacional Comum Curricular (BRASIL, 2018). Nessa perspectiva, entendemos que:

É na interação com os pares e com adultos que as crianças vão constituindo um modo próprio de agir, sentir e pensar e vão descobrindo que existem outros modos de vida, pessoas diferentes, com outros pontos de vista. Conforme vivem suas primeiras experiências sociais (na família, na instituição escolar, na coletividade), constroem percepções e questionamentos sobre si e sobre os outros, diferenciandose e, simultaneamente, identificando- se como seres individuais e sociais (BRASIL, 2018, p. 40).

Como faríamos isso em pleno distanciamento social? Tínhamos total clareza de que estávamos vivendo uma pandemia e nossa prioridade é sobreviver, tendo a criança prioridade absoluta! Reconhecemos que não estávamos preparadas para lidar com essa nova situação e todos estamos aprendendo com o processo. Feito isso, buscamos ressignificar nossa prática levando em consideração as diferentes realidades e necessidades das crianças e de sua família. Era perceptível que, assim como nós, essas famílias enfrentavam a sobrecarga de uma jornada que incluía o concílio entre vida profissional, acadêmica e doméstica.

\footnotetext{
${ }^{3}$ Procuramos registrar essa ação no Sistema Integrado de Gestão de Atividades Acadêmicas (SIGAA) da UFAL, prática que se realiza na instituição desde 2016, por meio do projeto de extensão "A Formação Continuada e em Serviço de Profissionais que Atuam na Educação Infantil: desafios e Possibilidades no NDI/UFAL”, coordenado pela professora e pesquisadora Aline da Silva Ferreira Aderne, no intuito de formalizar práticas de formação continuada e em serviço existentes na instituição e certificar todos os envolvidos.
} 
Há alguns anos, adotamos na instituição a criação de grupos de WhatsApp para nossas turmas. Por meio desses grupos, dialogamos e trocamos informações relacionadas com nossa turma e com os/as responsáveis. Com o distanciamento social, nosso grupo de sala se constituiu em um espaço de acompanhamento, escuta e apoio às famílias. Em nossa turma, a adesão das famílias é geral, e essa adesão, com o esforço e o envolvimento dessas famílias, foi utilizada em nosso favor, pois possibilitaria a continuidade da assistência às crianças, mesmo de forma limitada. Seguiríamos, então, com nossa escuta e fala, esclarecendo dúvidas e fornecendo informações por meio de textos, reportagens e sugestões de propostas que poderiam ser realizadas em casa e respeitassem sua vivência, a rotina e realidades.

O projeto segue por duas vias: sugestões semanais no grupo de sala e em encontros virtuais quinzenais ou mensais via Zoom, sendo esse segundo momento pensado no intuito de matarmos a saudade. As propostas incluem momentos de leitura, sessão de cinema, preparação de receitas culinárias e refeições, organização da rotina das crianças, apreciação de álbuns de fotografias, brincadeira com lanternas, banho de bacia, banho de bonecas e brinquedos. Essas sugestões vêm sendo lançadas por nós uma vez por semana e acompanhadas diariamente, havendo diálogo entre a equipe de sala e as famílias, que costumam fazer registros. Nos dois casos, a participação das crianças é voluntária, sem nenhuma exigência ou obrigatoriedade, assim como os registros dessas práticas por parte das famílias. Um desses registros será apresentado a seguir:

Prezadas professoras e auxiliares do Maternal II,
Parabenizo e agradeço a todos pelo excelente trabalho a distância que têm realizado
com nossos filhos, durante a quarentena devido ao Covid-I9 (coronavírus). Em
particular, minha filha Ana Rafaella ${ }^{4}$ tem-se desenvolvido bastante durante este
período de isolamento, uma vez que as atividades enviadas, bem como as
videoconferências, têm sido fundamentais nesse processo de aprendizagem. Ela se
tem mostrado muito interessada e se diverte com as atividades propostas.
Com certeza, este contexto que estamos vivendo (aliás, sobrevivendo) é muito
preocupante e, diante de tantas angústias e incertezas, devemos fazer nossa parte e
transmitir confiança aos nossos filhos. Com efeito, Ana Rafaella tem-se mostrado
preocupada (do jeito dela de criança) com os devidos cuidados como o uso de
máscara, higienização das mãos e entende que ainda não pode estar perto dos
amiguinhos da escola, apesar de sentir muita falta deles e de todos vocês. Ela fala o
tempo todo que fará uma festa e chamará todos os seus amiguinhos quando 'o
coronavírus for embora'. Vive brincando de fazer festinha (é o que mais gosta de
fazer), faz minha cama de palco para cantar 'Let it go' e também de pula-pula, faz
maquiagem e as unhas das bonecas, veste minhas roupas e calça, meus sapatos (na

${ }^{4} \mathrm{Em}$ conformidade com os aspectos éticos da pesquisa, a publicação do texto e do nome da criança foi devidamente autorizada pelos responsáveis. 
escola, ela gosta de usar fantasias), me ajuda a fazer bolos, vitaminas e sucos. Pretende ir à praia e à casa da vovó quando tudo isso passar. Suas cores preferidas são o azul e o rosa, e seu animal preferido é o cavalo (adora andar a cavalo). $O$ isolamento, sem dúvida nenhuma, é muito difícil, mas acredito que este seja um período de fortalecer os laços familiares, principalmente a atenção para nossos filhos. Essa fase passará e, em breve, estaremos juntos novamente.

Um grande abraço de Ana Rafaella e Alessandra! (MÃE).

O texto, enviado em 5 de maio de 2020, é fruto de uma das propostas lançadas, em que sugerimos a escrita de uma carta produzida pela família e pela criança, destinada à turma. A sugestão era de que fossem registradas suas impressões e sensações durante o distanciamento social, o que estavam fazendo, suas preferências e tudo o que achassem divertido e interessante.

\section{Algumas considerações}

Vivemos um momento totalmente novo e atípico e fomos levadas a repensar e a ressignificar nossas ações nos diferentes campos de nossa vida. Na educação infantil, não é diferente e, em meio a singularidades e especificidades, redescobrimos outros caminhos e outras possibilidades de aprendizagem.

Sobre o projeto "Acolhimento e Exploração de Mundo na Infância: vivências no maternal 2 antes, durante e depois do distanciamento social”, consideramos que o envolvimento das crianças e o comprometimento das famílias tem sido muito bom. No caso das sugestões propostas, temos obtido retorno significativo, por meio de imagens, vídeos e depoimentos, tanto das crianças quanto das famílias. Entendemos que tem sido positivo porque, segundo relatos das famílias, apesar das tensões e preocupações, as crianças têm-se divertido e os vínculos familiares têm-se fortalecido.

O simples fato de conseguirmos manter uma rede de apoio, para nós, já é uma conquista. Contudo, se por um lado as crianças abraçaram as sugestões, o mesmo não se verificou de imediato nos encontros virtuais. A princípio, algumas crianças ficaram curiosas, mas outras resistiram. Somente a partir do mês de junho, sentimos que algumas delas ficaram à vontade pela primeira vez.

Compreendemos que o presente relato se trata de uma experiência nossa e não um modelo ou formato defendido. Não sabemos ainda quando o distanciamento social terminará e não há previsão de retorno nas instituições educacionais no formato presencial. Enquanto 
isso não ocorre, pretendemos continuar respeitando o direito da criança, considerando suas necessidades e realidades, e aprendendo com esse processo.

\section{Referências}

BRASIL. Lei n. ${ }^{\circ} 9.394$, de 20 de dezembro de 1996. Estabelece as diretrizes e bases da educação nacional. Diário Oficial da União, Brasília, seção I, v. I34, n. 248, p. 27.83427.84I, 23 dez. 1996.

BRASIL. Ministério da Educação. Secretaria de Educação Básica. Diretrizes curriculares nacionais para a educação infantil. Brasília: MEC; SEB, 2010.

BRASIL. Ministério da Educação. Secretaria da Educação Básica. Base nacional comum curricular. Brasília, 2018. Disponível em: http://basenacionalcomum.mec.gov.br/images/BNCC_EI_EF_I I05 I8_versaofinal_site.pdf. Acesso em: 10 mar. 2020.

BRASIL. Ministério da Educação. Portaria n. ${ }^{\circ}$ 343, de 17 de março de 2020. Dispõe sobre a substituição das aulas presenciais por aulas em meios digitais enquanto durar a situação de pandemia do Novo Coronavírus - COVID-19. Diário Oficial da União, Brasília, 18 mar. 2020. Disponível em: http://www.in.gov.br/en/web/dou/-/portaria-n-343-de-I7-de-marco-de2020-248564376. Acesso em: 14 mar. 2020.

SOCIEDADE BRASILEIRA DE PEDIATRIA (SBP). Grupo de Trabalho Saúde na Era Digital (20I9-202I). Manual de orientação: \#menos telas \#mais saúde. 2019. Disponível em: https://www.sbp.com.br/fileadmin/user_upload/_22246c-ManOrient_-

_MenosTelas__MaisSaude.pdf. Acesso em: 14 mar. 2020.

Recebido em: 16 de junho de 2020.

Versão corrigida recebida em: 16 de setembro de 2020.

Aceito em: 30 de setembro de 2020.

Publicado online em: 04 de junho de 2021.

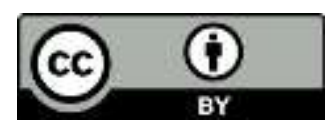

Olhar de professor, Ponta Grossa, v. 24, p. I-8, e-16|84.055, 202 I.

Disponível em <https://revistas2.uepg.br/index.php/olhardeprofessor> 